\title{
Framework for Pharmacy Services Quality Improvement- A Bridge to Cross the Quality Chasm
}

\author{
Part I. The Opportunity and the Tool
}

FREDERIC R. CURTISS, PhD, RPh, CEBS; RICHARD N. FRY, BSPharm, RPh; and STEVEN G. AVEY, MS, RPh

\begin{abstract}
OBJECTIVE: To review the literature on the subject of quality improvement principles and methods applied to pharmacy services and to describe a framework for current and future efforts in pharmacy services quality improvement and effective drug therapy management.
\end{abstract}

BACKGROUND: The Academy of Managed Care Pharmacy produced the Catalog of Pharmacy Quality Indicators in 1997, followed by the Summary of National Pharmacy Quality Measures in February 1999. In April 2002, AMCP introduced Pharmacy's Framework for Drug Therapy Management in the 21st Century. The Framework documents include a self-assessment tool that details more than 250 specific "components" that describe tasks, behaviors, skills, functions, duties, and responsibilities that contribute to meeting customer expectations for effective drug therapy management.

FINDINGS: There are many opportunities for quality improvement in clinical, service, and cost outcomes related to drug therapy management. These may include patient safety; incidence of medical errors; adverse drug events; patient adherence to therapy; attainment of target goals of blood pressure, glucose, and lipid levels; risk reduction for adverse cardiac events and osteoporotic-related fractures; patient satisfaction; risk of hospitalization or mortality; and cost of care. Health care practitioners can measure improvements in health care quality in several ways including (a) a better patient outcome at the same cost, (b) the same patient outcome at lower cost, (c) a better patient outcome at lower cost, or (d) a significantly better patient outcome at moderately higher cost.

Measurement makes effective management possible. A framework of component factors (e.g., tasks) is necessary to facilitate changes in the key processes and critical factors that will help individual practitioners and health care systems meet customer expectations in regard to drug therapy, thus improving these outcomes.

CONCLUSIONS: Quality improvement in health care services in the United States will be made in incremental changes that rely on a structure-process-outcome model. The structure is provided by evidence created from controlled randomized trials and other studies of care and system outcomes that are based on the scientific method. The process portion is created by the application of evidence in the form of clinical practice guidelines, clinical practice models, and self-assessment tools such as Pharmacy's Framework for Drug Therapy Management. Incremental changes in structure and process will result in the desirable outcome of meeting customer needs for more effective drug therapy and disease management.

KEYWORDS: Drug therapy management, Quality improvement, Pharmacy services

J Manag Care Pharm. 2004;10(1):60-78

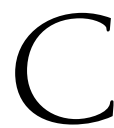

ertainly, the popular view is that current health care is the best that the world has ever seen. However, despite impressive accomplishments over the last 100 years, current clinical performance still falls far short of its potential.

The Institute of Medicine's (IOM's) Roundtable on Quality catalogued a startlingly broad array of failures in applying extant knowledge to routine care. ${ }^{1}$ Other reports extended that list. $^{2}$ For example, Schuster et al. found that, across all care delivery settings, only $52 \%$ of eligible adults older than 65 years received recommended yearly influenza vaccination, and only $28 \%$ received indicated pneumococcal vaccination. Overall, just $50 \%$ of Americans receive appropriate preventive care; only $70 \%$ of patients suffering from acute disease receive indicated acute care, while 30\% receive contraindicated therapies; and only $60 \%$ of those treated for chronic conditions received recommended care, and 20\% received contraindicated treatments. ${ }^{3}$ More recently, the IOM's Committee on Quality of Health Care in America described the wide scope of care-related injuries patients suffer in U.S. hospitals ${ }^{4}$ and, in a second report, Crossing the Quality Chasm: A New Health System for the 21st Century," called for massive redesign of the health care delivery system to address system-wide failures of execution. ${ }^{5}$

Bridging the gap between the state of the current health care system and the system that patients expect and need is an overwhelming task for all health care disciplines. Pharmacy is no exception. While much attention is devoted to the controversial and sometimes imperfect methods for selecting appropriate drug therapy, administrators, policy makers, and even pharmacists and other health care professionals too often overlook the enormous opportunity to improve drug therapy outcomes through monitoring and managing what happens after the selection of the drug. Pharmacy practice is, or should be, man-

\section{Authors}

FREDERIC R. CURTISS, PhD, RPh, CEBS, is editor-in-chief of the Journal of Managed Care Pharmacy; RICHARD N. FRY, BSPHARM, RPh, is director of programs and STEVEN G. AVEY, MS, RPh, is the executive director of the Foundation for Managed Care Pharmacy, Alexandria, Virginia.

AUTHOR CORRESPONDENCE AND REPRINT REQUESTS: Fred Curtiss at the Academy of Managed Care Pharmacy or Richard Fry or Steve Avey at the Foundation for Managed Care Pharmacy, 100 North Pitt St., Suite 400, Alexandria, Virginia 22314. Tel: (800) 827-2627; Fax: (703) 683-8417; E-mail: fcurtiss@amcp.org; rfry@fmcpnet.org; savey@fmcpnet.org

Copyright $\odot$ 2004, Academy of Managed Care Pharmacy. All rights reserved. 
aging patient care and assuring appropriate drug therapy outcomes. While pharmacists have long possessed the requisite knowledge and skills to take the lead in managing drug therapy, the profession has lacked a long-term vision - a road mapfor drug therapy management built on effectively evaluating and meeting customers' needs and expectations. According to Albert Wertheimer, PhD, "Neither pharmaceutical care nor managed care solicits the views of customers/clients as to what they want, and what they are willing to pay for."

Recognizing the need to fill this void, the Academy of Managed Care Pharmacy (AMCP) created a task force early in 1999 to design Pharmacy's Framework for Drug Therapy Management in the 21st Century. To fulfill this objective, AMCP developed a strategic plan to create a model for drug therapy management: the Framework will support a long-term vision for managing drug therapy that is currently lacking in the profession. The Framework started from the building block of customer expectations. It provides health care systems, pharmacists, and other health care practitioners with a tool to systematically analyze whether drug therapy management can be responsive to those expectations, and, if so, to change processes and/or to develop action plans to describe and evaluate how to realistically meet those expectations and then analyze the expected outcome in terms of the customer expectations. The Framework has been created to be nonspecific relative to practice setting or disease and with the ability to adapt roles and procedures to meet the needs of various enterprises.

\section{Concerns Regarding the Quality of U.S. Health Care}

As the following examples illustrate, providing quality health care and appropriate prescribing, monitoring, and management of drug therapy provide largely unmet opportunities for improvement. The IOM report, Crossing the Quality Chasm, published in March 2001, was a milestone in identification of the sources of the "quality gap" in health care in the United States that threatens the health and safety of too many patients. ${ }^{5}$ This Chasm report followed the flashpoint 1999 IOM report, To Err Is Human: Building a Safer Health System that estimated that adverse events occur in $2.9 \%$ to $3.7 \%$ of hospital admissions, causing 44,000 to 98,000 deaths each year, and that one half of these hospital adverse events are avoidable. ${ }^{4}$

In April 2003, the Midwest Business Group on Health released an updated version of their study, Reducing the Costs of Poor-Quality Health Care through Responsible Purchasing Leadership. Based primarily on findings and extrapolations from the published literature and expert analysis, the authors estimate that $30 \%$ of all health care outlays today are the result of poor-quality care, consisting of overuse, misuse, and waste (Table 1). Using a 2001 health expenditure figure of $\$ 1.4$ trillion, the authors estimate that the United States wastes $\$ 420$ billion each year as a direct result of poor quality. Breaking down the financial costs further, they estimate that poor quali-

\begin{tabular}{|c|c|c|}
\hline Error type & Definition & Example \\
\hline Misuse & $\begin{array}{l}\text { An appropriate medical service } \\
\text { is selected, but a preventable } \\
\text { complication occurs and } \\
\text { the patient does not receive } \\
\text { the full benefit of the service }\end{array}$ & $\begin{array}{l}\text { An error in the calculation } \\
\text { of a dose of digoxin } \\
\text { results in an overdose } \\
\text { and subsequent death } \\
\text { of the patient }\end{array}$ \\
\hline Dveruse & $\begin{array}{l}\text { The potential for harm exceeds } \\
\text { the potential for benefit in } \\
\text { the provision of the medical } \\
\text { service }\end{array}$ & $\begin{array}{l}\text { An antibiotic is prescribed } \\
\text { for an otherwise healthy } \\
\text { 30-year-old with a viral } \\
\text { upper respiratory tract } \\
\text { infection }\end{array}$ \\
\hline Jnderuse & $\begin{array}{l}\text { There is a failure to provide } \\
\text { a health care service when it } \\
\text { would have produced a } \\
\text { favorable patient outcome }\end{array}$ & $\begin{array}{l}\text { A patient develops } \\
\text { measles at age } 26 \text { months } \\
\text { because the vaccine dose } \\
\text { was missed at age } \\
12 \text { months }\end{array}$ \\
\hline
\end{tabular}

* Adapted from Yetman RJ. Preventing misuse errors in health care organizations. J Clin Outcomes Manage. August 2001;29-33; Kohn LT, Corrigan JM, Donaldson MS (eds.). To Err Is Human: Building a Safer Health System. Washington, DC: National Academy Press; 2000; and AHRQ: Medical Errors: The Scope of the Problem-An Epidemic of Errors. Available at: http://www.ahcpr.gov/qual/errback.htm. Accessed August 18, 2002

\begin{tabular}{|c|c|c|}
\hline Term & Definition & Example \\
\hline Medical error (ME) & $\begin{array}{l}\text { A failure to complete } \\
\text { a planned action as } \\
\text { intended or the use } \\
\text { of a wrong plan to } \\
\text { achieve an aim }\end{array}$ & $\begin{array}{l}\text { Diagnostic error, such } \\
\text { as misdiagnosis leading to } \\
\text { an incorrect choice of } \\
\text { therapy; or failure to use } \\
\text { an indicated diagnostic } \\
\text { test; or misinterpretation } \\
\text { of test results; or failure } \\
\text { to act on abnormal results }\end{array}$ \\
\hline $\begin{array}{l}\text { Adverse medical } \\
\text { event (AME) }\end{array}$ & $\begin{array}{l}\text { An injury caused by } \\
\text { medical management } \\
\text { rather than by the } \\
\text { underlying disease or } \\
\text { condition of the patient }\end{array}$ & $\begin{array}{l}\text { Postsurgical wound } \\
\text { infections or other } \\
\text { nosocomial infections } \\
\text { caused by exposure } \\
\text { to hospital pathogens }\end{array}$ \\
\hline $\begin{array}{l}\text { Adverse drug } \\
\text { event (ADE) }\end{array}$ & $\begin{array}{l}\text { An injury that results } \\
\text { from the use of a drug }\end{array}$ & $\begin{array}{l}\text { Hip fracture caused by } \\
\text { lightheadedness associated } \\
\text { with use of an anti- } \\
\text { hypertensive drug }\end{array}$ \\
\hline
\end{tabular}

*Adapted from Yetman RJ. Preventing misuse errors in health care organizations. J Clin Outcomes Manage. August 2001;29-33.

ty health care costs an individual U.S. employer between $\$ 1,900$ and $\$ 2,250$ per employee per year. ${ }^{7}$ This cost was specifically attributable to $\$ 1,500$ in direct costs and another $\$ 400$ to $\$ 750$ in indirect costs, such as lost workdays, per covered employee. 
On July 24 2002, the Joint Commission on Accreditation of Healthcare Organizations (JCAHO, Oakbrook Terrace, IL) released its National Patient Safety Goals for 2003 to focus on the "confusion in identifying patients, miscommunication among caregivers, wrong-site surgery, infusion pumps, medication mix-ups and clinical alarm systems." "For each of the National Patient Safety Goals, there are clear, evidence-based Recommendations to help health care organizations reduce specific types of health care errors. Beginning January 1, 2003, the more than 17,000 JCAHO-accredited health care organizations that provide care relevant to the Goals will be evaluated for compliance with the Recommendations or implementation of acceptable alternatives." Dennis S. O'Leary, MD, president of JCAHO, said, "The know-how to prevent these errors exists. We now need to focus on making sure that health care organizations are actually taking these preventive steps."

The 2003 National Patient Safety Goals and Recommendations are:

Goal 1: Improve the accuracy of patient identification.

Recommendations:

a. Use at least 2 patient identifiers (neither to be the patient's room number) whenever taking blood samples or administering medications or blood products

b. Prior to the start of any surgical or invasive procedure, conduct a final verification process, such as a "time out," to confirm the correct patient, procedure, and site, using active—not passive—communication techniques.

Goal 2: Improve the effectiveness of communication among caregivers.

Recommendations:

a. Implement a process for taking verbal or telephone orders that requires a verification "read-back" of the complete order by the person receiving the order

b. Standardize the abbreviations, acronyms, and symbols used throughout the organization, including a list of abbreviations, acronyms, and symbols not to use.

Goal 3: Improve the safety of using high-alert medications.

Recommendations:

a. Remove concentrated electrolytes (including, but not limited to, potassium chloride, potassium phosphate, sodium chloride $>0.9 \%$ ) from patient care units.

b. Standardize and limit the number of drug concentrations available in the organization.

Goal 4: Eliminate wrong-site, wrong-patient, and wrong-procedure surgery.

Recommendations:

a. Create and use a preoperative verification process, such as a checklist, to confirm that appropriate documents, (e.g., medical records, imaging studies) are available.

b. Implement a process to mark the surgical site and involve the patient in the marking process.

Goal 5: Improve the safety of using infusion pumps.

Recommendation:

a. Ensure free-flow protection on all general-use and PCA intravenous infusion pumps used in the organization.

Goal 6: Improve the effectiveness of clinical alarm systems.

Recommendations:

a. Implement regular preventive maintenance and testing of alarm systems.

b. Assure that alarms are activated with appropriate settings and are sufficiently audible with respect to distances and competing noise within the unit.

Note: The 2003 Goals were developed by an expert advisory group composed of physicians, nurses, risk managers, and other professionals. The Goals and related Recommendations were drawn from the 25 issues of JCAHO's patient safety newsletter Sentinel Event Alert. The advisory groups identified a total of 44 expert- and evidence-based recommendations from the publication that include the 11 associated with the 2003 Goals. The remaining Recommendations constitute an initial pool upon which future National Patient Safety Goals may be based. JCAHO expects to issue National Patient Safety Goals and Recommendations each year. Aggregate data on achievement of the Goals will be made public each year, and individual organization compliance information will be disclosed when the reformatting of JCAHO organization performance reports is completed in mid-2004.

The IOM report, To Err Is Human, focused public attention on the subjects of medical errors and adverse events. To fully grasp the import of this seminal work, the reader must develop an understanding of the nomenclature of quality improvement (Table 2). It is important to note that some adverse drug events (ADEs) are not preventable, and they reflect the risk associated with treatment, such as a life-threatening allergic reaction to a drug when the patient had no known allergies to the drug. ${ }^{8}$ However, a preventable ADE occurs when a patient receives an antibiotic to which he or she is known to be allergic, experiences anaphylactic shock, and dies.

There is considerable controversy regarding the estimated incidence of medical errors (MEs) and adverse medical events
(AMEs) versus the true incidence of MEs and AMEs. ${ }^{9-11}$ For ADEs specifically, including adverse drug reactions (ADRs), the opportunity for quality improvement may be larger than the available measures would suggest. A study performed in January and February 2001 found that a combination of patient and provider interviews revealed a total of 83 ADEs in 51 patients, or at least $1 \mathrm{ADE}$ in $26 \%$ of patients, versus $1 \mathrm{ADE}$ ( $0.5 \%$ rate) determined by a passive ADE reporting system. ${ }^{12}$ A report in December 1999 from the Office of the Inspector General, U.S. Department of Health \& Human Services, found that "a low percentage of ADR reports is being sent to the U.S. Food and Drug Administration (FDA)" resulting in a situation in which the "FDA does not know the magnitude of the ADR 
problem nor whether progress is being made in reducing the number of serious ADRs." ${ }^{13}$

While most drug errors do not result in patient harm, studies have shown that many are preventable. ${ }^{14}$ In the institutional environment, a study of 4,031 nonobstetrical adult admissions to 2 Boston tertiary care hospitals found 247 ADEs, a rate of 6.5 ADEs per 100 admissions, of which $43 \%$ were either fatal, life-threatening, or "serious"; $28 \%$ of all ADEs and $42 \%$ of serious ADEs were judged preventable. ${ }^{15}$ Higher rates of ADEs have been found in nursing homes. In 18 Massachusetts nursing homes, 546 ADEs were found during 2,403 resident years of observation, a rate of 22.7 ADEs per 100 resident-years; 44\% were fatal, life threatening, or serious; $51 \%$ of all ADEs and $72 \%$ of serious ADEs were judged preventable. ${ }^{16}$

Drug therapy in the elderly has been criticized for being fraught with too many avoidable errors, including headlines such as, "Docs Giving Many Seniors Wrong Drugs." ${ }^{17}$ Some recent research findings have suggested that there have been meaningful improvements in the quality of medication use in elderly patients since 1987. Using data from the 1996 Medical Expenditure Panel Survey, Zhan and colleagues ${ }^{18}$ reported that the use of some inappropriate medications had declined substantially over the 10-year study period. Nevertheless, this study's authors concluded that, in 1996, almost 1 million community-dwelling elderly individuals received at least 1 of the 11 drugs that an expert panel had determined should always be avoided by elderly patients.

Unfortunately, information related to the incidence of preventable ADEs in the ambulatory geriatric population is limited. However, a 12-month study conducted between July 1999 and June 2000 by Gurwitz and colleagues concluded that the incidence of ADEs in this population was 50 per 1,000 personyears, with a rate of 13.8 preventable ADEs per 1,000 person years. This $5 \%$ rate per year appears to be reliable since it was derived from a cohort study of 30,397 person-years of observation using 6 methods of detecting drug-related incidents: (1) reports from health care providers (obtained from mail report cards, an ADE telephone hot line, and an intranet reporting system), (2) review of hospital discharge summaries, (3) review of emergency department notes, (4) computer-generated signals, (5) automated free-text review of electronic clinic notes, and (6) review of administrative incident reports for MEs. ${ }^{19}$ This study found that $27.6 \%$ of the ADEs were preventable, yielding an incidence of 1.38 preventable ADEs per 100 person-years. Among the $38 \%$ of the ADEs that were categorized as serious, life threatening, or fatal, the rate of preventable ADEs was higher, at $42 \%$. Patient adherence was a factor in $21 \%$ of the preventable ADEs, prescribing was a factor in $58 \%$, and the monitoring stage of pharmaceutical care was a factor in $61 \%$ of the preventable ADEs. Dispensing errors were rare, accounting for fewer than $2 \%$ of the preventable ADEs.

Patient safety as a rallying point has helped focus parallel and cooperative efforts among health care organizations and associations. For example, Pharmacy's Framework for Drug Therapy Management in the 21st Century melds effectively into the priorities set by the Joint Commission on Accreditation of Healthcare Organizations in its National Patient Safety Goals for 2003 (Figure 1). The Leapfrog Group, a coalition of more than 135 public and private organizations that provide health care benefits, has developed 3 patient safety standards that reward publicly transparent hospital performance..$^{20}$ In May 2003, the National Quality Forum (NQF), a private, nonprofit public benefit corporation created in 1999 to develop and implement a national strategy for health care quality measurement and reporting, released its consensus report, Safe Practices for Better Healthcare. The report details 30 health care safe practices that NQF members think should be universally utilized in applicable clinical care settings to reduce the risk of harm to patients. These "voluntary consensus standards" were reviewed and endorsed by the more than $150 \mathrm{NQF}$ member organizations, which include consumer groups, purchasers, payers, health care providers, and government agencies. ${ }^{21}$

There is no dispute that patient safety is paramount, but there is disagreement about (a) the magnitude of the quality chasm in pharmacy services, (b) what constitutes a quality defect, (c) the important quality benchmark measures, and (d) what is necessary to change in the processes in the delivery of pharmacy and other related services to meet customer expectations and to prevent quality defects. However, effective drug therapy management involves more than maximizing patient safety, and some physicians have recognized that "improving the quality of medication use," particularly in the higher-risk elderly, requires "enhanced collaborations between those who prescribe drugs and those who know medications best (clinical pharmacists)." ${ }^{\prime 19}$

\section{Evidence of the Effect of Pharmacist Interventions on Outcomes}

"Because of the immense variety and complexity of medications now available, it is impossible for nurses or doctors to keep up with all of the information required for safe medication use. The pharmacist has become an essential resource... and thus access to his or her expertise must be possible at all times." Institute of Medicine, To Err Is Human, $2000 .^{4}$

As the 21st century dawned, pharmacy faced new challenges. Rising demand for prescription drugs and prior projections of an over-supply of pharmacists significantly strained the supply of pharmacists-the Pew Health Professions Commission report in 1996 inaccurately predicted "an excess of 40,000 pharmacists by 2005."22 In this sense, pharmacy had to do more with fewer human resources in the first years of the 21 st century. At the same time, public perception in 2003 placed pharmacists above physicians in ratings of honesty and 
ethical standards and second only to nurses by these measures. ${ }^{23}$

An update in 2002 on the subject of measuring the value of clinical pharmacist interventions focused on the need for rigorous research designs that include a control group and randomization of patients, whenever possible..$^{24}$ In this subject review, Malone cited the design and results of the IMPROVE study that enrolled 1,054 patients from 9 VA medical centers and randomized 523 subjects to ambulatory clinical pharmacy services plus usual medical care and 531 subjects to usual medical care only. There were no differences found in SF-36 scores or patient satisfaction ${ }^{25}$ or in the measure of overall resource utilization. ${ }^{26}$ By a fourth measure, reduction in total cholesterol (TC) and low-density lipoprotein (LDL), the pharmacy intervention group showed statistically greater reductions compared with the control group. Since both groups showed reductions in LDL and TC, the inclusion of a control group permitted attribution of the LDL and TC reductions to the pharmacist intervention rather than to other factors such as system-wide cholesterol reduction efforts. The IMPROVE study also found that total medical care costs were not greater in the pharmacist intervention group, demonstrating improved efficiency; i.e., improved patient outcomes (reduction in TC and LDL) at the same cost.

Outside of the hospital, some have suggested that pharmacists are part of the problem, ignoring electronic drug-interaction messages from drug claims processors and not counseling patients. ${ }^{27}$ Conversely, others have shown that clinical pharmacists reduce the incidence of ADEs and improve quality of care. A study of admissions to the intensive care units (ICU) at Brigham and Women's Hospital in Boston found an incidence of 10.4 preventable ADEs per 1,000 ICU patient days. When clinical pharmacists were assigned to work in the ICU, the incidence of ADEs was reduced by $66 \%$ to 3.5 per $1,000 \mathrm{ICU}$ patient days. ${ }^{28}$ The study design was a before-after, controlgroup design in which baseline ADE incidence was followed by a pharmacist involved in patient rounds with residents, nurses, and attending staff each morning and on-call consult throughout the day, activities that consumed about one half of the clinical pharmacist's time.

Recent drug product withdrawals highlight opportunities for pharmacists to reduce the incidence of potential ADEs. Physician misprescribing and poor adherence to FDA prescribing guidelines were determined to be factors in the market withdrawal of troglitazone and cisapride early in 2000, alosetron late in 2000, and cerivastatin in mid-2001. For example, $85 \%$ of 270 side-effect reports on cisapride were in patients with risks outlined in the drug's label; only $10 \%$ of patients on troglitazone received the full monthly regimen of recommended monitoring tests, and liver function tests recommended by the FDA on the label for troglitazone resulted in only $45 \%$ of troglitazone patients receiving the baseline test. Full compliance with the liver function monitoring regimen was only $9.3 \%$ after 1 month and less than $3 \%$ after 3 months. ${ }^{29}$ Poor physician adherence to black-box warnings in FDA-approved product labeling has also been documented for isotretinoin and metformin. ${ }^{30,31}$ In one large-scale review, almost one quarter of patients with a prescription for metformin had 1 or more absolute contraindications. ${ }^{32}$ The authors concluded that physicians might frequently prescribe metformin inappropriately despite black-box contraindications.

Local programs and projects have demonstrated favorable effects of community pharmacist interventions. In one of the longest-running demonstration projects, the city of Asheville, North Carolina, began paying community pharmacists in 1997 to counsel beneficiaries with diabetes in diet, nutrition, exercise, and glycemic control in the hope of reducing complications of the disease. ${ }^{33}$ The diabetes management program began as a 6-month pilot project, but initial results, including favorable reactions from beneficiaries, resulted in retention and expansion of the "Asheville Project." Five years later, the Asheville Project had expanded to involve the 3 largest employers in the area: the hospital, city of Asheville, and a paper company. The city of Asheville compensated community pharmacists for clinical interventions involving patients with asthma, hypertension, hypercholesterolemia, and diabetes. Anecdotes from patients attributed behavior change such as regular walking, strict attention to glucose monitoring, daily aspirin use, better asthma control, and use of fewer inhalers to regular pharmacist counseling. As one retired Asheville city employee said, the Asheville Project using community pharmacists "gives you the knowledge, the equipment, and the incentive to control your own destiny." ${ }^{34}$

More thorough analysis of the Asheville Project suggested that pharmaceutical care services (PCS), including patient education, training in the use of self-monitored blood glucose meters, clinical assessment, patient monitoring, follow-up, and referral, had measurable effects on clinical, humanistic, and cost outcomes. In the short term, PCS was associated with improved hemoglobin Alc, improved patient satisfaction with pharmacy services, and an $87 \%$ increase in direct medical disease-specific costs (\$52 per-patient-per-month [PPPM]). However, these services brought about a 29\% decrease in nondiabetes costs (\$134 PPPM) and a 16\% decrease in all-diagnosis costs (\$82 PPPM). ${ }^{35}$ The percentage of patients with optimal hemoglobin Alc increased from about $40 \%$ at baseline to more than $60 \%$ during the first 18 months of follow-up. ${ }^{36}$ Cost outcomes showed a reduction of $\$ 1,200$ (39\%) per-patient-per-year in total mean direct medical costs.

Acceptance of these pharmacist-provided services appears to be growing among certain physician groups. Data from national surveys of medical groups performed by the Medical Group Management Association and the American Medical Group Association suggest that physicians are increasingly embracing pharmacist consultant services. Pharmacist services were provided by $49.5 \%$ of single specialty medical groups in 2001 , up 
from $37.4 \%$ in 2000 , and pharmacist services in multispecialty medical groups increased from $49.1 \%$ in 2000 to $56.0 \%$ in $2001 .^{37}$ The practical implication of this increase in pharmacist consultant services in medical groups in 2001 is perhaps best seen in small medical groups of 5 to 6 physicians and 7 to 9 physicians, where pharmacist consultant services increased by a relative $25 \%$ from 2000 to 2001 , from $40.8 \%$ to $51.3 \%$ and from $37.7 \%$ to $49.2 \%$, respectively.

Collaboration between physicians and pharmacists not only has the potential to improve drug therapy outcomes but critical evaluation of collaborative practice has also demonstrated such outcomes. The quality of therapeutic determinations made by pharmacists within a collaborative practice was studied by a 12-member panel of physicians and pharmacists. Using randomly selected patient records, the peer-review panel found 5,780 drug therapy problems that were resolved for 2,524 patients receiving pharmaceutical care from this collaborative practice. Achievement of therapeutic goals was found to improve from $74 \%$ of patients at the time of the initial pharmaceutical care encounters to $89 \%$ at the latest encounters, and the decisions made by the pharmaceutical care practitioners working in collaboration with physicians to provide drug therapy management services were judged by the peer reviewers to be clinically credible..$^{38}$

\section{Creating Pharmacy's Framework-Focus on the Customer}

For nearly 3 years, more than 100 drug therapy specialists, experts, and pharmacists involved daily in drug therapy management spent more than 3,000 hours creating this resource for others dedicated to improving patient drug therapy. Although the scope of the Framework Project originally focused on managed care pharmacy, the authors found the concepts and objectives to be universal for any individual or organization concerned with drug therapy management. For this reason, they broadened the scope of the project to incorporate all practice settings within the profession of pharmacy.

The first steps in the strategic plan involved determining what functions are desired by patients, health care practitioners, payers, insurers, employers, physicians, policymakers, and academicians and then to determine who should have responsibility for that component. What sets the Framework Project apart from previous studies of pharmacy is the focus on listening to large numbers of customers/patients in planning drug therapy management services for the future that are setting- or environment-independent.

The Framework Project evolved, including thoughtful examination of the work of others who studied pharmacy practice and pharmacy education in the 20th century. The 1927 report Basic Material for a Pharmaceutical Curriculum set the standard for the 4-year undergraduate pharmacy curriculum. The American Pharmaceutical Association (APhA) Dichter Report in 1973 focused on effective patient and customer communica- tion, and the 1975 Millis Commission Report highlighted future needs for "clinical scientists" trained in the behavioral sciences and lit the path toward adoption in 1999 of the 6-year PharmD entry-level program of study. Readers are also directed to the excellent, coincident work of other pharmacy professionals, notably the joint efforts of the National Association of Chain Drug Stores, APhA, and the Institute for Safe Medication Practices (ISMP) in the ISMP Medication Safety Self-Assessment for Community-Ambulatory Pharmacy, released in September 2001, ${ }^{39}$ and the American Society of Health-System Pharmacy in the ISMP Medication Safety Self Assessment (for institutional pharmacy). Both are available online at www.ismp.org.

The perspective is a 30,000 -foot view of the health care landscape. The Framework attempts to achieve universal applicability, with focus placed on fundamental elements of drug therapy management and with a focus on populations, while still maintaining the attention to patients as individuals. Thus, the Framework must be applied with the understanding that success in achieving drug therapy goals rests not only on changing attitudes, skills, or behaviors of individual practitioners but also on organizational change. This reflects the understanding that successful drug therapy management is a complex process and requires more than a single person to be carried out. This differs from the popularly held version of pharmacy, which is closely linked to product. The profession has internally focused models defining what a pharmacist is responsible for, but the Framework projects an external focus, with specific relevance to customer-driven and expressed expectations. It also addresses how health care systems, pharmacists, and other health care practitioners organize internally and externally to accomplish the mission.

The assumptions employed in building a Framework for pharmacy practice in the 21 st century included the following:

- Patients want to be healthy.

- Resources to pay for medication and therapy are finite.

- There is a segmented payer system and it will continue.

- Patients are at the center of the pharmacist's point of view.

- Drug therapy demands attention, and pharmacists are uniquely trained and positioned to provide it.

- The health care system is intended to maintain and improve health and to prevent and treat disease.

- Pharmacy should be accountable for the drug therapy process but is dependent on the cooperation of other health care professionals. ${ }^{40}$

One prominent and unique feature of the AMCP Framework Project was the very broad definition of pharmacy's customer. Specifically, AMCP solicited opinions and perceived needs from employers, academicians, government officials, health plan administrators, pharmaceutical manufacturers, patients, nurses, and physicians. Interviewers found that customer expectations were broad and diverse, reflecting the many types of customers of pharmacy services. So, what do customers want and expect 
from pharmacy? The answer is that customers expect much from pharmacists, in part because pharmacy has so many types of customers, often with diverse interests. In many ways, the Framework looks at pharmacy from the outside looking in rather than from the pharmacy perspective looking out.

Pharmacy customer expectations appeared to be grouped into some common themes:

- Patients will achieve appropriate drug therapy outcomes.

- Drug-related problems will be identified, resolved, and prevented.

- Care is coordinated and practitioners are competent.

- There is value in the care that patients receive and it is affordable.

- The system is accessible and is looking out for the patient's best interest.

- There is a professional covenant between the patient and practitioner.

- The system will provide adequate and appropriate information and education regarding appropriate drug use.

These pharmacy customer expectations closely parallel the "aims" for health care quality improvement in the 21 st century as defined in the IOM report Crossing the Quality Chasm. ${ }^{7}$ The aims are that health care quality improvement be

- safe,

- effective,

- patient-centered,

- timely,

- efficient, and

- equitable.

\section{Results of Customer Interviews}

Customer interviews demonstrated early in the Framework Project that customer expectations are often unfulfilled in the present drug therapy process. Shortfalls included (a) insufficient communication between physicians and pharmacists, (b) little structure and insufficient means to continuously monitor patient medication adherence and response to therapy, and (c) fragmentation throughout the drug-use process, all of which are particularly problematic for persons with complex or chronic disease(s). Insufficient communication was seen as a source of (avoidable) MEs. ${ }^{41}$

Interviewees identified these "abc" shortfalls in the present drug-use process as a particular threat to health and safety for patients with multiple prescribers and pharmacies. Effective drug therapy management is necessarily oriented to a continuous, longitudinal care management plan rather than episodic encounters with patients seeking one or more prescription drugs.

The proliferation of direct-to-consumer (DTC) advertising seemed to precipitate a common perception among pharmacy's customers, except for drug company representatives, that prescription drug manufacturers are driving demand for highercost drugs. Interviewed customers perceived this demand for higher-cost drugs to be fueled by DTC advertising and by aggressive drug promotion to physicians. Beyond these common areas of agreement among pharmacy customers were many areas of common disagreement. Drug benefit plans and health systems earned criticism for appearing to focus on the drug product rather than quality of pharmacy services. Health plan administrators, for their part, may point their "finger" at drug manufacturers who aggressively promote high-cost drugs to consumers and physicians while at the same time trumpeting their efforts to "partner with us [drug manufacturers] to contain costs." Health plan administrators also may find employer interest in disease management programs, in concept, but greater interest in (premium) cost than in quality of care.

Physicians tended to be opposed or at least cautious about how much pharmacists should know about patient clinical information and how to manage their accessibility to the patient medical record. The implications of this caution are potentially disturbing given the obvious potential for quality improvement and little downside "risk" other than some small cost associated with providing pharmacist access to additional (complete) clinical information in the patient medical record. Interesting in the discussion and concern about medical errors is failure to recognize that the absence of adequate patient information at the point of care is one of the most significant contributors to MEs.

Patients believed that computer systems should be developed to link clinical patient data between the pharmacy and the physicians' offices (notwithstanding the efforts by the activists and politicians to "protect" the "privacy" of patient-specific information by making this information less accessible).

Among pharmacy customers, representatives of drug manufacturers were most likely to believe that the benefits of new drugs-reduced hospitalization and improvement in patient adherence through more convenient dosing regimens-outweigh the increase in drug costs for "new" drug therapies. This finding is not dramatic or surprising on its face and underscores the tug-of-war that takes place in justifying the additional costs of new drug therapies. Noteworthy and consistent with the quality improvement paradigm, patients and other pharmacy customers opined that an older drug taken twice per day may be a better choice (quality improvement) than a newer, highcost drug taken once per day.

More agreement among pharmacy's customers was found in the need for more useful and less-biased drug and health information. Pharmaceutical manufacturer representatives commonly produce readily available drug and health information. Customers noted the Internet as a possible source of useful drug and health information, but there was some skepticism about the accuracy and reliability of information obtained from this source. Although customers can find unbiased drug and health information, it is not common practice for physicians and pharmacies to independently perform the literature research necessary to locate, produce, and periodically update this information. 


\section{Coalescence of Quality Criteria and Process Steps Into a Self-Assessment Tool}

The professionals who worked on the Framework Project had one goal in mind-to use their collective experience and modicum of wisdom to help widen the perspective of all persons involved in drug therapy management. None of these professionals would presuppose that this is a "bible" or guideline for individuals or organizations to follow. Rather, each reader may use the Framework to help think about best practices and the paths that can lead to best patient outcomes. After all, the ultimate purpose is to improve heath care quality, measured in several ways including (a) a better patient outcome at the same cost, (b) the same patient outcome at lower cost, (c) a better patient outcome at lower cost, or (d) a significantly better patient outcome at moderately higher cost.

As the Framework development process progressed, the scope of pharmacy services to its customers necessary to meet the validated expectations appeared to coalesce in categories or core focus areas:

1. Fundamental skills, tasks, and functions are employed for effective drug therapy management.

2. Health management, health promotion, and disease prevention programs and services are offered.

3. The patient is effectively assessed, accurately diagnosed, and appropriate drug therapy is selected.

4. The patient is served by a distribution system that provides accurate drug therapy and understandable health information in a timely manner.

5. Patient response to drug therapy is monitored for effectiveness, adherence, and avoidance of adverse effects, and drug therapy is adjusted to achieve optimal outcomes.

6. Medical benefits are provided through a system that has an appropriate drug-use policy and benefit design.

7. The health system performs ongoing assessment to ensure that the results of drug therapy management lead to healthy individuals and populations.

The hundreds of tasks or components of drug therapy management within the 7 core focus areas are aggregated within "functional areas." While these core focus areas and the functional areas within these core focus areas will appear familiar to almost all readers, some of the specific tasks or "components" may be unfamiliar. Some readers may even find themselves challenging the relevance of some components to pharmacy services and delivery systems today. This response is expected for some components. Contributors to the Framework Project recognized that pharmacy practice and drug therapy management are not site- or setting-specific, and thus not all of the core focus areas will have relevance to every pharmacy organization. Framework contributors encourage all to help set the "bar" ever higher in drug therapy management for all practice sites, environments, and delivery models.

This Framework applies to technicians, professionals, clerks, and administrative personnel because effective drug therapy management requires multidisciplinary cooperation and coordination of effort and long-term vision and support from managers and administrators. Accordingly, the term "health care practitioners" used in the Framework includes managers, administrative support staff, pharmacists, pharmacy technicians, and other health professionals and support staff. The assessment tool is sufficiently flexible to be used by individual pharmacists, health-system pharmacists, managers, administrators, or organizations.

Effective use of this tool for drug therapy management requires some judgment. Therefore, to determine the role of pharmacy in assuring appropriate medication therapy within the health care delivery system, it is necessary to ascertain the expectations and valued functions performed surrounding the drug-use process from the perspectives of stakeholders. The goal is to determine key competencies brought by the pharmacist, validate a list of functions that need to be performed for appropriate medication therapy, and determine those functions where the pharmacist can be an appropriate and effective provider. The final product will be a bridge and a toolset to assist in moving competencies to the prescribed level from its present place. $^{6}$

\section{The Framework's Foundation-Self-Assessment}

The Self-Assessment Tool ${ }^{42}$ is the foundation of the Framework portfolio. Its more than 250 specific "components" describe tasks, skills, and functions that contribute to meeting customer expectations for effective drug therapy management. The purpose of the assessment tool is to provide perspective- a framework - and the means to periodically assess organization and individual performance in key functional areas of drug therapy management. The assessment tool places the patient and the quality of care at the center of pharmacy services. Interestingly, the application of 6 Sigma methods in the Bridges to Excellence program championed by General Electric resulted in the Quality Functional Deployment tool, a quality improvement instrument that resembles the Framework Self-Assessment Tool. ${ }^{43}$

As listed previously, there are 7 core focus areas in the Grid and Self-Assessment Tool. The first core focus area addresses components that are applicable whenever a health care practitioner is interacting with patients. Components include key critical and pervasive skills that are fundamental to effective drug therapy management, such as interpersonal communication, leadership, patient education, and quality improvement through feedback. Core focus areas 2 through 7 are organized in a sequence that follows care processes of patients if they progress logically through the health care system. The core focus areas are organized so that they may be used either sequentially or as freestanding units. Therefore, just as some patients or other customers will only require services listed under one or two ore focus areas, so health care practitioners 


\section{FIGURE 2 Framework Grid and Self-Assessment Tool-User's Instructions}

The Framework is a collection of tools designed to help individual pharmacists and organizations (i.e., health plans, pharmacy benefit managers, pharmacy chains, hospital pharmacy departments, etc.) improve the management of drug therapy for patients through a system of continuous quality improvement. You might envision a committee that knows it needs to improve the way its organization manages asthma patients but is not quite sure how to do it. You might be an individual pharmacist in a pharmacy and decide you want to do a better job serving your patients. The Framework can help you accomplish that. The Grid and Self-Assessment Tool is at the heart of this process.

How does it work?

Organizations and individual practitioners may take different approaches when using the Grid and Self-Assessment Tool to achieve care improvement goal(s) such as:

System or practice assessments

1. The individual or group within an organization reads through the Grid and Self-Assessment Tool, choosing those components (behaviors, skills, functions, duties, responsibilities, etc.) that best describe effective drug therapy management for its particular practice setting.

2. Use the "Does This Apply?" column to indicate whether the component is applicable to you or your organization.

3. After you read a component, rate yourself or your organization according to the degree to which the component skill, function, or task is achieved or performed (i.e., never do it, sometimes do it, usually do it, always do it).

Suggested evaluation parameters:

- Never: $<25 \%$ of the time, not data supported

- Sometimes: $26 \%-50 \%$ of the time

- Usually: $51 \%-75 \%$ of the time

- Always: $76 \%-100 \%$ of the time

4. Next, record the level of importance of the component to you or your organization. If it is important to you and you are not doing very well, develop an action plan that will help you meet the goals that will ultimately help you comply with that specific component.

5. For example:

Core Focus Area \#2: Health management, health promotion, and disease prevention programs and services are offered.

Functional Area 2.2 Outreach and Accessibility

\begin{tabular}{|l|l|l|l|l|l|l|l|}
\hline & \multicolumn{1}{|c|}{ Component } & $\begin{array}{c}\text { Does } \\
\text { This Apply?** }\end{array}$ & Never & Sometimes & Usually & $\begin{array}{c}\text { Always } \\
\text { Almportance }\end{array}$ & $\begin{array}{c}\text { Action Plan } \\
\text { Reference Number }\end{array}$ \\
\hline 2.2 .5 & $\begin{array}{l}\text { Health management, } \\
\text { health promotion, and } \\
\text { disease prevention programs } \\
\text { (including support materials) } \\
\text { are conducted in languages that } \\
\text { are predominant in the target } \\
\text { population and are sensitive } \\
\text { to cultural differences among } \\
\text { ethnic populations. }\end{array}$ & Yes & & XXX & & & High \\
\hline
\end{tabular}

6. Enter an action plan reference number into the last column. Then develop an action plan related to this component that would define measurable goals to help improve communications and outreach efforts to members who have English as a second language.

7. The action plan should include the following elements:

a. defined, measurable goals,

b. a time frame for accomplishing defined goals,

c. the amount of resources that will be required,

d. how goals will be measured, and

e. who is responsible for the elements of the action plan.

8. Of course, you will need to develop specific action plans to address each area that is targeted for improvement. The Framework portfolio includes template examples of action plans.

\section{Targeted Problem Assessment}

The first step involves determining what functions regarding drug therapy management are needed by payers, insurers, employers, physicians, and patients, and then to determine who should have responsibility for that component.

For example, using the MCO experience detailed in the accompanying Brent James paper Making It Easy to Do It Right as an example, you have determined that inadequate and inappropriate prescribing of discharge medications for patients hospitalized with heart disease is contributing to increased morbidity and mortality among your covered members, resulting in increased hospital and emergency department costs. These steps would be followed in applying the Framework:

1. Rate your organization against those components that directly affect the development and implementation of evidence-based prescribing guidelines for discharge medications for patients hospitalized with heart disease and monitoring of their drug therapy outcomes postdischarge.

2. As described above, develop action plans for those components rated as deficient and having a high degree of importance that will help your organization achieve target goals for improving the drug therapy management for this group of patients.

3. Once the components rated as "high" have been improved, begin to focus on those of moderate importance, then those deemed of lower importance.

To conclude, the skills, functions, tasks, responsibilities, etc., necessary to meet customer needs may encompasses one, two, or more core focus areas. Therefore, the Framework user will choose to evaluate and develop action plans only for those portions of the Grid and Self-Assessment Tool that address individual or organizational needs. 
may only concentrate on one or two core focus areas. The portions of the Grid and Self-Assessment Tool the health care practitioner chooses to use will be those that address the individual customer's needs.

The "component" tasks, skills, and functions in each of the core focus areas are categorized under "functional areas" of drug therapy management. The components under a given function$\mathrm{al}$ area are building blocks that interact to permit the health care practitioner or the system to achieve successful patient care. The components are explicitly not limited to site or practice settings but are applicable across a broad array of care environments. Some component skills and behaviors pervade all of the core focus areas. Where this is the case, the Self-Assessment Tool includes each component in the most applicable core focus area with cross-references. Likewise, a few of the functional areas, such as Patient Education and Continuous Quality Improvement, are common to 2 or more core focus areas. A balance between redundancy and readability has been attempted in the core focus areas, functional areas, and components in the assessment tool. Users should view the 7 core focus areas comprehensively, not as individual, stand-alone core focus areas.

The self-assessment scale allows the user to identify whether the component is of importance. If it is, the scale permits the user to rank the incidence of each component from "never" perform this task or function to "sometimes," "usually," or "always." The level of importance of various components and tasks will differ among individuals and organizations. The combination of the "level of importance" and the incidence rate (never, sometimes, usually, always) helps establish priorities for quality improvement for a given organization, pharmacy, or individual health care practitioner. See Figure 2 for a representation of the Grid and Self-Assessment Tool.

The final column of the Self-Assessment Tool allows the user to enter the "action plan reference number." The action plan for improvement will be different for each user. The organization or individual user can outline an action plan and give it an identifiable number.

The ultimate objective is not the computation of an overall "score" for the organization. Rather, the purpose of the assessment tool is to provide perspective, a framework, and the means to periodically assess individual and organization performance in meeting customers' needs in key functional areas of effective drug therapy management. ${ }^{42}$

The components under a given functional area are building blocks that interact to permit the health care practitioner or the system to achieve successful patient care outcomes. Organizations and individuals should evaluate those components in the assessment tool specific to the needs of their customers. Thus, an organization may identify only 3 or 4 components on which to focus quality improvement efforts. The Framework portfolio includes an action plan template to further help users put the Framework to practical use.

\section{Creating an Action Plan}

The real power of the Framework tool is in the development and use of an action plan. If an individual or organization reads the Framework documents and does a self-assessment but does nothing to institute change, then the process has been of little value. After an assessment has been completed and the individual or organization determines the components that have the highest priority to them, they should develop an action plan that will enable them to make the needed changes. The Framework portfolio includes examples of action plans. Of course, the individual users will need to develop specific action plans to address each area they target for improvement.

Action plans usually define the exact goals that are set by individuals or organizations. It is important to remember that goals need to be measurable. This allows the user to rate how well they are doing with their quality improvement process. An example of a poor goal is: Our organization will do a better job of educating our patients on the usage of their medication to improve overall health. Because there is no specific quality measure, this organization will not be able to determine if they are improving or not. An example of a measurable goal is: Our organization will improve the overall health of our diabetic patients by implementing an education and monitoring program that allows us to measure their daily fasting blood sugar levels and monthly hemoglobin Alc values. Once this organization has base-line values for a subpopulation of patients with diabetes, progress to goal can be measured.

There are a number of other important elements of an action plan. These include the time frame desired, the amount of resources that will be required, how goals will be measured, and who is responsible for the action plan. When all of the critical elements are identified in an action plan, the opportunity for success improves dramatically.

\section{The Framework's Core Focus Areas- Issues and Opportunities}

The following sections summarize some of the key issues and opportunities enumerated in the Self-Assessment Tool related to improving drug therapy for pharmacy's customers. A few examples from the Grid and Self-Assessment Tool are shown in Figure 3.

\section{Core Focus Area 1: Employ Fundamental Skills, Tasks, and Functions for Effective Drug Therapy Management}

The components within Core Focus Area 1 are building blocks for drug therapy management. Fundamental communication skills include the text and materials written and produced in multiple languages, at the appropriate reading-comprehension level, the avoidance of jargon, and the use of interpersonal communication techniques to reduce misunderstanding and establish rapport. Behaviors that help reduce misunderstanding in interpersonal communication also promote a sense of caring 


\section{FIGURE 3 Examples From the Framework Grid and Self-Assessment Tool}

Functional Area 3.2 Drug Selection
\begin{tabular}{|c|l|c|c|c|c|c|c|}
\hline & \multicolumn{1}{|c|}{ Component } & $\begin{array}{c}\text { Does This } \\
\text { Apply?** }\end{array}$ & Never & Sometimes & Usually & $\begin{array}{c}\text { Always } \\
\text { Ampel of } \\
\text { Importance }\end{array}$ & $\begin{array}{c}\text { Action Plan } \\
\text { Reference } \\
\text { Number }\end{array}$ \\
\hline 3.2 .3 & $\begin{array}{l}\text { Asymptomatic or otherwise stable patient } \\
\text { health status is used as an opportunity to } \\
\text { reduce or eliminate drug therapy (e.g., } \\
\text { reduction in dose or frequency of acid- } \\
\text { suppression therapy). }\end{array}$ & & & & & & \\
\end{tabular}

Functional Area 3.3 Drug Prescribing

\begin{tabular}{|c|l|c|c|c|c|c|c|}
\hline & \multicolumn{1}{|c|}{ Component } & $\begin{array}{c}\text { Does } \\
\text { This } \\
\text { Apply?** }\end{array}$ & Never & Sometimes & Usually & $\begin{array}{c}\text { Always } \\
\text { Almportance }\end{array}$ & $\begin{array}{c}\text { Action Plan } \\
\text { Reference } \\
\text { Number }\end{array}$ \\
\hline 3.3 .2 & $\begin{array}{l}\text { Drug therapy is prescribed in accordance } \\
\text { with a treatment plan that clearly indicates } \\
\text { the goals of therapy and specifies when drug } \\
\text { therapy should be reevaluated, changed, } \\
\text { adjusted, or discontinued. }\end{array}$ & & & & & & \\
\hline
\end{tabular}

Functional Area 5.1 Patient Monitoring \& Documentation

\begin{tabular}{|c|c|c|c|c|c|c|c|}
\hline & \multicolumn{1}{|c|}{ Component } & $\begin{array}{c}\text { Does } \\
\text { This } \\
\text { Apply?** }\end{array}$ & Never & Sometimes & Usually & $\begin{array}{c}\text { Level of } \\
\text { Always }\end{array}$ & $\begin{array}{c}\text { Action Plan } \\
\text { Reference } \\
\text { Number }\end{array}$ \\
\hline 5.1 .6 & $\begin{array}{l}\text { On each occasion in which a patient obtains } \\
\text { services, the health care practitioner uses the } \\
\text { opportunity to assess existing drug therapies. } \\
\begin{array}{l}\text { For example, upon a prescription refill, the } \\
\text { pharmacist discusses with the patient the } \\
\text { response to drug therapy, including untoward } \\
\text { effects, and the pharmacist evaluates patient } \\
\text { adherence to therapy. }\end{array}\end{array}$ & & & & & & \\
\hline
\end{tabular}

Functional Area 7.1 Drug Therapy Evaluation

\begin{tabular}{|c|l|c|c|c|c|c|c|}
\hline & \multicolumn{1}{|c|}{ Component } & $\begin{array}{c}\text { Does } \\
\text { This } \\
\text { Apply?** }\end{array}$ & Never & Sometimes & Usually & $\begin{array}{c}\text { Level of } \\
\text { Always }\end{array}$ & $\begin{array}{c}\text { Action Plan } \\
\text { Reference } \\
\text { Number }\end{array}$ \\
\hline 7.1 .5 & $\begin{array}{l}\text { Patient feedback is used as a tool to improve } \\
\text { drug therapy outcomes for individual patients } \\
\text { and as a means to improve care processes } \\
\text { and treatment guidelines. }\end{array}$ & & & & & \\
\hline
\end{tabular}

**Does the component apply to the individual, the practice, or the organization?

and respect. Effective patient education depends on the combination of knowledge and the ability to communicate effectively and caringly. Leadership involves the skills and behaviors that make others want to excel in their individual work. Leadership ensures that mission statements and strategic goals are continuously reviewed and revised, providing the framework for operational policies and procedures that deliver the best care, all of the time.

Pharmacy leaders create work environments that continually change and improve based on customer feedback. These work environments use feedback-positive and negative-to teach and inspire workers. Patients are protected by skill docu- mentation and policies and procedures that permit measurement, communication, and follow-through, and, hence, continuous quality improvement.

Satisfaction with care and care providers is an important outcome, and its measure can help define quality along with clinical outcomes and cost outcomes. Effective drug therapy management includes quality improvement in patient satisfaction, attained through the use of fundamental provider skills, benefit design, and resource commitment to an infrastructure (e.g., an electronic patient medical record with reliable and efficient access) that supports the immediate transfer of clinical and health information among diverse care settings. 
Fundamental communication skills. The first step in more effective communications skills is to understand and embrace a behavioral change model-attitude, recognition, acceptance, and change. A person is not likely to improve communication skills while possessing the attitude that "I know everything that I need to know to be effective at interpersonal communication." Attitude can be an important barrier to more effective communication since most people believe that they are good (effective) listeners. Second in the change (improvement) process is recognition that misunderstanding is the normal result of the communication process. Accepting the fact that misunderstanding is the normal result of the communication process allows a person to adopt behaviors (change) that will help reduce misunderstanding.

Effective interpersonal communication skills such as repeat back can be used to protect patient safety as well as improve drug therapy management. The Agency for Healthcare Research and Quality (AHRQ) in its 640-page report, Making Health Care Safer: A Critical Analysis of Patient Safety Practices, released in July 2001, ${ }^{44}$ stated that 11 of 73 "patient safety practices" are supported by evidence from research, including "asking that patients recall and restate what they have been told during the informed-consent process." Unfortunately, AHRQ found that most hospitals and nursing homes do not routinely perform even the 11 top-ranked safety practices. Among the tools that can be used to improve patient safety, better communication among physicians, nurses, and pharmacists was judged capable of preventing $86 \%$ of potentially harmful ADEs compared with $81 \%$ potentially preventable with ward-based clinical pharmacists and $76 \%$ potentially preventable with computerized physician-order entry. ${ }^{45}$

Privacy of personal health information is another customer expectation that requires fundamental skills that span all dimensions of effective drug therapy management. Privacy expectations pertain to oral communication and protection of personal health information from disclosure to unintended parties for unacceptable purposes such as product marketing.

The IOM Chasm report proposed a fundamental change in access to personal health information. ${ }^{5}$ The premise is that a better-informed patient is a safer patient. Better-informed patients can participate more actively in their own care, including protection from accidental injury resulting from medical and drug interventions. The IOM Chasm report proposed an unprecedented openness of medical record information, electronic or otherwise, in the 21st century, embracing the model that open access to information can inspire trust and better engage patients in their own care.

Leadership is more than management and governance, and according to the American Society for Quality, it is the first of 7 broad topics within the quality management "body of knowledge." ${ }^{46}$ Leaders help create a corporate culture that prizes and rewards excellence. Excellent corporate cultures allow failure. In fact, defects can be viewed as treasures, providing information to improve products and services and avoid future defects.
The excellent organization continuously searches for defects, researches the defects for causes, and, without assigning blame, changes the procedures and processes to prevent future defects.

Continuous quality improvement includes the premise that elimination of defects will reduce the cost of errors and reduce the cost of health care in the United States. This paradigm of reducing the cost of health care by improving the quality of health care is a difficult concept for many to accept. Don Berwick, in his insightful piece titled As Good As It Should Get: Making Health Care Better in the New Millennium, ${ }^{47}$ makes the case that we need examples of methods to take us to a higher level of quality and efficiency in health care. "What is needed is a compilation of the very best practices and features, which are embodied in organized delivery systems that

- use safety science techniques to drive error rates continually lower;

- practice and promote prevention seriously;

- create a seamless, timely delivery of care flow for all patients;

- involve patients and families fully in their own care and offer patients increasing control over decisions that affect them;

- break down the walls of intimidation and misunderstanding among professionals, patients, and families;

- perform no scientifically groundless treatments; and

- formally search for effective, proven care practices and assure that patients benefit reliably from such appropriate care."

\section{Core Focus Area 2: Health Management, Health Promotion, and Disease Prevention Programs and Services Are Offered}

Evidence suggests that lifestyle changes and health promotion activities have as much influence over health as does pharmacotherapy. Pharmacists are typically more accessible than many other health care practitioners and therefore are in a position to provide counsel, advice, and tools to help individuals adopt lifestyle changes and seek health-risk screening opportunities. Effective health management includes program outreach in which population risk-profiles are developed to identify and notify persons who would be likely to benefit most from health promotion intervention efforts.

Effective drug therapy management includes the perspective that the most effective drug therapy for a given patient may be no drug therapy at all. Within this conceptual framework is the potential value of disease prevention and health promotion in avoidance of the need for pharmacotherapy. Serum cholesterol reduction to target lipid levels through pharmacotherapy reduces the risk of heart attacks. Serum cholesterol reduction to target lipid levels through lifestyle changes (e.g., diet and exercise) results in quality improvement by avoiding pharmacotherapy and its costs; i.e., same outcome at lower cost.

Effective health promotion includes disease prevention through health-risk screening as well as education and methods to affect health behaviors. Effective drug therapy management is more 
than getting the right drug to the right patient in the right dose at the right time at an affordable price. Effective drug therapy management includes the prospective identification of persons at risk and those who would benefit from pharmacotherapy as well as health risk reduction and promotion of healthy lifestyles to optimize patient outcomes.

All pharmacists have a responsibility to be aware of or at least to guide customers to valid and reliable sources of health information. Clinical practitioners offer and provide this information through patient encounters. Managed care pharmacists in administrative positions have the responsibility to assist clinicians by supporting the development and availability of tools such as paper and electronic education materials on health promotion and disease prevention, including tools that are independent of drug therapy. The importance of these tools is underscored for persons at risk, including older persons at risk of falls, incontinence, dementia, and hearing loss. ${ }^{48}$ The pharmacist can help all persons and, in particular, persons at risk, to locate useful guidelines and patient education materials and make these materials and information readily available at the point of care.

\section{Core Focus Area 3: The Patient Is Effectively Assessed, Accurately Diagnosed, and Appropriate Drug Therapy Is Selected}

Effective and safe drug therapy depends on accurate and complete patient diagnosis. This includes assessment of health risk associated with unhealthy lifestyle behaviors, environmental factors, genetic and/or familial predisposition, and susceptibility to future disease and disease complications. Selection of the proper therapeutic agent and dose includes identification and evaluation of unique patient factors, including considerations such as drug therapy in the elderly, pediatric dosing, and patient-specific characteristics such as compromised renal or hepatic function, history of treatment failure, and alternate therapy due to previous ADRs. Drug therapy management includes the efficient and errorfree transmission of prescription orders to dispensing pharmacists and the sharing and coordination of patient-specific information among all practitioners involved in the selection and administration of pharmacotherapy to patients.

So-called "collaborative practice" became a mainstream topic in the United States in 2002 and 2003 and part of government recommendations in a Medicare Payment Advisory Commission (MedPAC) report in mid-June 2002. MedPAC recommended that "The Secretary should assess models for collaborative drug therapy management services in outpatient settings." ${ }^{\prime 49}$ The MedPAC report in June 2002 represented a milestone in public debate about the value of clinical pharmacy services. The following tasks performed by clinical pharmacists engaged in collaborative practice agreements with physicians are not surprising in the context of the realization that persons aged 65 years and older account for $13 \%$ of the population but consume $35 \%$ of all prescription drugs in the United States each year ${ }^{49, p, 23}$ :

- assist physicians to improve medication management and continuity of care;

- select, initiate, modify, continue, discontinue, and monitor patients' drug therapy;

- order, perform, and interpret medication-related laboratory tests;

- assess patients' responses to therapy;

- counsel and educate patients on medications; and

- administer medications.

As of June 2003, all but 11 states permitted pharmacists to administer drug therapy pursuant to a collaborative drug therapy management (CDTM) agreement with a prescriber or a physician's order, and, in one state, managed care organization (MCO) pharmacists perform CDTM services under the state medical practice act, which allows physicians to delegate prescribing authority. ${ }^{50}$ The primary vehicle for CDTM involves development of patient-specific treatment protocols agreed to by the patient, physician, and pharmacist.

There is nothing in Core Focus Area 3 and its "grid" of components that assumes that pharmacists are routinely involved in patient diagnosis or even in drug prescribing. There is, however, a clear mandate from pharmacy customers that pharmacists have access to sufficient patient-specific information to be able to assess the appropriateness of the prescribed drug therapy, including dose and duration of therapy. Customers expect pharmacists to double-check the "fit" between the prescribed drug therapy and the patient-specific conditions. ${ }^{41}$ This check by the pharmacist at the initiation of therapy necessarily involves assessment, and ongoing patient monitoring involves additional clinical assessment of the patient.

Selecting the appropriate drug therapy involves some expectation of effectiveness, which implies that evidence exists to support the expectation. As pointed out in the IOM Chasm report, many aspects of health care are associated with little or no evidence of either effectiveness or ineffectiveness. ${ }^{5}$

\section{Core Focus Area 4: The Patient Is Served by a Distribution System That Provides Accurate Drug Therapy and Understandable Health Information in a Timely Manner}

The drug therapy "product" involves more than drug distribution and dispensing. It includes sufficient useful and accessible information to guide practitioners and the patient to the decisions that are most likely to produce the best drug therapy outcomes. Pharmacy practitioners can improve their effectiveness in patient education and health behaviors by involving and engaging patients, such as in the evaluation of their individual progress in their care management plan. Component tasks in this core focus area also include seemingly mundane but very important functions related to drug distribution, including product storage, product safety, security to prevent tampering or diversion, clean preparation and dispensing areas, and methods to respond quickly and efficiently to product recall notices. Best practice in pharmacy also includes triage and risk management strategies for major environmental events (e.g., earth- 
quakes, tornadoes), temporary interruptions in supply (e.g., asthma inhalers, voluntary product recalls, raw material shortages, manufacturing problems), or unexpected spikes in demand (e.g., influenza epidemic, stockpiling, bioterrorism).

Pharmacy customers who use drug therapy have the reasonable expectation that they will receive the correct drug in the correct dose and strength, with 100\% accuracy, every time. This zero-defect expectation imposes the highest standards of accuracy and performance at all steps in the medication-use system, yet the evidence suggests that, while remarkably low in frequency, pharmacy dispensing errors that have the potential to cause patient harm or discomfort occur at an apparent rate of about 1 in 1,000 prescriptions..$^{51}$ Pharmacy customers also expect to obtain drug therapy and pharmacy services through a process that is convenient, approachable, and affordable.

Pharmacy has an increasingly large opportunity to help patients and clinicians sort through the mountains of data and "information" available in journals, the lay press, and the Internet. The Framework Project, with its interviews of customers, revealed a nearly self-evident fact-patients expect pharmacists to help them sort through the data to find the information that will lead to optimal drug therapy outcomes, including efficacy and safety. ${ }^{41}$ However, the challenge to pharmacists and other health care professionals to differentiate truth from pseudoscience is, quite simply, daunting. The explosion of material available through the Internet makes this challenge to define evidence nearly impossible for individuals. In addition to the challenge of differentiating good information from bad data, the advent of DTC advertising in the late 1990s increased customer awareness of and demand for the promoted drugs.

Pharmacy customer interviews show that the scope of the information expected by patients extends beyond drug information to health information. A survey of patients with hypercholesterolemia, who had a lipoprotein profile performed within the 6 months preceding the survey, showed that patients want to be involved in their drug therapy; $94 \%$ of the survey respondents preferred to receive notification of all lab test results, whether normal or abnormal, and desired that recommendations for health management changes accompany abnormal test results. ${ }^{52}$ Research results have established that patient involvement in care decisions improves patient satisfaction and adherence to therapy, in part by reducing decisional conflict and indecision about the value of treatment. ${ }^{53}$ Quality improvement as measured by adherence to therapy can occur as a result of soliciting patient treatment preferences prior to the selection of initial therapy. ${ }^{54}$

\section{Core Focus Area 5: Patient Response to Drug Therapy Is Monitored for Effectiveness, Adherence, Avoidance of Adverse Effects, and Drug Therapy Is Adjusted to Achieve Optimal Outcomes}

Components within this core focus area present perhaps the most significant opportunities for effective drug therapy management.
Critical elements to improve outcomes include a systematic process to track drug errors and prevent, detect, and resolve ADEs as well as measure patient response to therapy and adjust drug therapy based on this feedback. From this perspective, patients who do not return for care are potential failures, not successes.

From a care-flow perspective, a care treatment plan is a necessary part of every episode of drug therapy and is the first step in drug therapy management. The plan permits continuous quality improvement in the care of each patient, achieved through application of the P-D-C-A (plan, do, check, act) quality-improvement tool. Patient progress can then be assessed relative to the care treatment plan and appropriate adjustments made to initial drug and dose selections. Reliance on evidence in the care process will lead to more-predictable and higherquality patient outcomes. Monitoring intermediate and ultimate patient outcomes and making continuous adjustments increases favorable outcomes and reduces undesirable outcomes. Continuous assessment includes the prevention, identification, and treatment of ADEs.

Routine access to a patient's entire drug history by his or her pharmacist and physicians is necessary to help avoid druginduced disease as well as attain optimum drug therapy outcomes. But the need and expectation remain unfulfilled. For patients who see more than one physician, their multiple prescribers seldom have efficient access to information on the entire drug-use history. Core Focus Area 5 includes assessment of pharmacist access to sufficient patient information to support decisions on the effectiveness of drug therapy, development of drug-induced disease, ADEs, and the need to make dosage or drug selection changes. In pharmacy customer interviews in the Framework Project, academicians, drug manufacturers, employer-purchasers, patients, health plan administrators, and, to a more limited extent, physicians and government administrators, agreed that pharmacists should have access to complete patient clinical data. ${ }^{55}$

Construction of the care treatment plan for each patient should be specific to patient diagnosis and individual patient characteristics (e.g., age, ethnicity, socioeconomic status, and living environment) and reflect current standards of care. By definition, care guidelines, clinical practice models (CPMs), and treatment protocols are not static and should be subject to continuous quality improvement. Unfortunately, even high-profile sources of clinical practice guidelines (CPGs) may not be reliable. Work published in September 2001 in the Journal of the American Medical Association found that only 3 of 17 (18\%) of the CPGs published by AHRQ were judged to be still valid. ${ }^{56}$ Seven (41\%) of the CPGs were found to require a major update to reflect new evidence, and 6 CPGs were judged to require a "minor update." In other words, at the time of the report in September 2001, three quarters of the AHRQ guidelines needed updating. Early in 2003, AHRQ launched the Web-based National Quality Measures Clearinghouse to function as a repository for evidencebased quality measures and measure sets. ${ }^{57}$ In addition to the 
shortfall in maintaining and updating available CPGs and CPMs, a major challenge for pharmacy and medicine in the 21st century involves delivery of the clinically relevant information to the practitioner at the point of care. Even the best clinical guidelines will have no effect on patient outcomes if not used. Unfortunately, research has shown that the development and dissemination of practice guidelines has minimal effect on clinical practice..$^{58-61}$

The Committee on Quality of Health Care in America of the IOM recommended in its Chasm report in 2001 the development of a clinical-information infrastructure that would eliminate most handwritten clinical data by 2010. Brent James, MD, has long advocated the placement of clinically relevant information not only at the time of service but also in the process of care such that a clinical information system generates reminders for each patient, in a manner that makes the information unavoidable to the clinician. ${ }^{62}$ Research by Dexter et al. showed in a randomized controlled trial that a computerized clinicalinformation system that generated preventive care reminders at the point of patient discharge increased significantly the use of subcutaneous heparin for patients at risk for venous thromboembolism, instructions to take aspirin for patients hospitalized for acute myocardial infarction, and the use of pneumococcal or influenza vaccine for eligible patients. ${ }^{63}$

An information technology-based clinical decision support system may not be necessary to improve the quality of care, but such a system is necessary to reduce significantly the variance in practice and to maximize favorable therapeutic outcomes. This perspective is consistent with the observation attributed to Mark Twain: "We cannot possibly know everything we need to know, the subject is simply too large." Lawrence Weed observed in 1997, "Until now, we have believed that the best way to transmit knowledge from its source to its use in patient care is to first load the knowledge into human minds ... and then expect those minds, at great expense, to apply the knowledge to those who need it. However, there are enormous 'voltage drops' along this transmission line for medical knowledge." ${ }^{\prime 4}$

\section{Core Focus Area 6: Medical Benefits Are Provided Through a System That Has an Appropriate Drug-Use Policy and Benefit Design}

This core focus area concentrates on the management of processes and the collating and sharing of information to assure that health benefits are adequate, make sense, and are generally straightforward to use. The health benefit should facilitate the provision of appropriate drug therapy such that practitioners have adequate time to develop professional relationships with patients, collect key-critical monitoring data, record this information, and make midcourse changes to improve drug therapy outcomes. To achieve this goal, the health benefit should include coverage for tasks and interventions that generate maximum output and best outcomes with limited resources.

Organizations measure effective drug therapy management, as all health service functions, by efficiency-achieving a better outcome at the same cost, the same outcome at lower cost, a better outcome at lower cost, or a significantly better outcome at moderately higher cost. "Cost" is a necessary consideration in this value determination since health care resources are finite, and a dollar spent on one good or service potentially reduces availability for spending on an alternate good or service. Second, whether commercial health insurance plans, government programs, or personal resources finance drug therapy, its cost affects the entire population. From the payer perspective, effective drug therapy management depends on more than the medical benefit to finance tasks and interventions. It also depends on responsible and effective management and leadership. Effective leaders and managers develop tools, procedures, and processes to generate maximum output with limited resources.

Commonly, the medical benefit and drug benefit design specific to a patient influence the selection of the most preferred drug therapy for that patient. Drug benefit designs commonly have financial incentives such as different copays for use of generic drugs and preferred drugs, and multi-tier plans with additional copays for "nonpreferred" or nonformulary branded drugs. Pharmacy and therapeutics (P\&T) committees make these decisions regarding preferred drugs long before the individual patient encounter. From this perspective, health care systems must recognize all of the expectations of pharmacy's customers regarding fair-balance and absence of bias in evaluating alternate drug therapies. Just as the prescriber selects the best drug therapy for an individual patient, health care systems that operate P\&T committees have the same or greater responsibility to protect preferred therapy decisions from bias and to base decisions on the best available evidence on clinical, service, and cost outcomes. ${ }^{65}$

However, drug-cost considerations are not as simple as the cost of the drug itself. The occurrence of an avoidable ADE increases the cost of therapy. An avoided ADE may reduce the cost of therapy. Aspirin prevents coronary heart disease, and even after accounting for the costs associated with the increased incidence of major bleeding, it is the most cost-effective therapy for reducing the medical and hospital costs associated with coronary events accross patients at a wide range of coronary risks ${ }^{66}$ Ultimately, drug costs are not "pharmacy" costs but health care costs, where cost "silos" for pharmacy versus physicians versus hospitals or home care are melded. Prescription drug benefits and pharmacy benefit managers contribute to total health care costs and should not be divorced or carved out from the larger perspective.

\section{Core Focus Area 7: The Health System Performs Ongoing Assessment to Ensure That the Results of Drug Therapy Management Lead to Healthy Individuals and Populations}

The emphasis in Core Focus Area 7 is on the evaluation of col- 
lective, aggregate data to improve outcomes and processes for individual patients and across the hundreds, thousands, and even millions of patients, care-encounters, and care management plans. The determination of favorable patient care outcomes includes the development of quality measures for health care services and participation in their continuous development as well as continuous improvement in the processes of collecting data and the measurement of performance against available standards. Reliable clinical data are necessary for the conduct of valuable studies of the effects of interventions on population health. Readers should be critical of "quality standards" since these standards are always evolutionary. Readers should also strive to be informed of the criticisms of others and knowledgeable about shortcomings in existing quality measures. For example, the Health Plan Employer Data and Information Set (HEDIS) 2000 quality standard for asthma control was criticized for having little to do with true asthma control. ${ }^{67}$

Widespread use of integrated electronic medical records will facilitate the capture of patient clinical values in a more reliable manner, improving data quality as well as increasing efficiency in the collection and analysis of patient clinical data. The opportunity looms large. Consider that in 2001 just 33\% of MCOs and integrated health networks (IHNs) reported using an integrated electronic medical record. This represented a very modest increase over previous years when 31\% of MCOs and IHNs reported using an electronic medical record in 1999 and 27\% in 1997. ${ }^{68}$ As for the magnitude of the chasm between current practice and quality standards established by the Leapfrog Group, in 2001, only 3.3\% of hospitals reported operational physician electronic order entry systems, and, in 2002, fewer than $5 \%$ of hospitals had computerized order-entry systems to permit detection of possible medication errors. ${ }^{69}$

Finally, it is not possible to do all things for all people. Resource consumption and return on investment must be fundamental considerations in quality improvement in health care and pharmacy services. To achieve the promise of disease management, health care systems must invest in higher-quality databases of medical encounter information combined with more valid and reliable descriptions of patient characteristics. Application of the principles of continuous quality improvement will ensure continual reassessment of the soundness of the resource allocation decisions and permit changes in medical and pharmacy intervention methods, processes, and procedures to cross the quality chasm. Somehow, we must continually strive to measure and improve health care quality and the measures of health care quality without diverting resources from other efforts that have better potential to actually improve quality. This is not a temporal concern and deserves our attention far into the 21 st century.

\section{Discussion}

The IOM Chasm report set forth in useful detail the gap between the desired health care system of the 21st century and the defi- ciencies in the present health care system. As useful as the IOM Chasm report is, it could have defined more clearly the fundamental cause of many of the deficiencies of the present system. That is, the current health care system is directed primarily by market forces that do not reward or invest in quality. Arnold Relman, MD, of Harvard Medical School, observed, "The multiple independent private insurers (mostly investor-owned) constantly seek to reduce their payments to providers and their financial obligations to sick patients. . . In all parts of the system, the providers of care (i.e., hospitals and physicians) see themselves as competing businesses struggling to survive in a hostile economic climate, and act accordingly. The predictable result is a fragmented, inefficient, and expensive system that neglects those who cannot pay, scrimps on support of public health services and medical education, and has all of the deficiencies in quality that are so well described and analyzed in this [Chasm] report. It is a system that responds more to the financial interests of investors, managers, and employers than to the medical needs of patients."

From another perspective, efficiency is one of the valuable outcomes of quality improvement, and tools such as Pharmacy's Framework will permit individual pharmacists and pharmacies and managed health care systems in the 21st century to focus investments in quality to increase efficiency and improve patient outcomes. The great strides in the 21 st century in managed care pharmacy will involve less focus on pharmacy provider discounts and more emphasis on methods to reduce overuse and misuse of pharmacy services and improve underuse of pharmacy services. This quality improvement will occur, in part, through enhanced 2-way communication between managed health care systems and pharmacy providers. PBMs will become coordinators of care and less brokers of pharmacy provider discounts.

In the Framework portfolio white paper, "Organization Culture and Effecting Change in Pharmacy in the 21st Century," Jeanine Mount writes, "Optimizing drug therapy management presents the greatest challenge to pharmacy as it enters the 21 st century. Meeting this challenge requires seizing opportunities and overcoming obstacles that limit pharmacy's current contribution to health care. In short, it requires changing pharmacy practice. "Initiating change can be daunting, however this is a time when the amount and pace of change is unprecedented. Observe this for long enough and it becomes clear that one's choices are simple: actively manage change, reactively respond to change, or be left behind."70

Within Pharmacy's Framework for Drug Therapy Management in the 21st Century is a new structure to identify and meet the needs of pharmacy's customers and optimize drug therapy. The Framework authors view it as a roadmap that can guide change. Pharmacy is more than managing the care of individual patients. Pharmacy involves organized efforts to continuously improve common methods and processes to attain better patient out- 
comes. Certainly no pharmacist, pharmacy, or health care system carries out all of the activities enumerated in the Framework. It is also safe to say that every pharmacist, pharmacy, and health care system engages in some of the Framework activities, although which and to what extent will vary considerably.

\section{Conclusion}

Using the Framework, every pharmacist, pharmacy, and health care system has the potential to bridge the quality gap through continuous self-assessment of performance in core focus areas and in the specific tasks and functions that comprise these core focus areas. The Framework tool can help better define the opportunities for quality improvement, narrow the focus for the interventions, and help in the measurement of the progress to goal.

The Pharmacy's Framework for Drug Therapy Management in the 21 st Century is available at www.fmcpnet.org.

\section{ACKNOWLEDGMENTS}

The Framework Project to define the future of pharmacy through effective drug therapy management benefited from the wisdom and insight of more than 100 volunteers and representatives of organizations as customers of pharmacy, including the American Association of Colleges of Pharmacy, American Association of Health Plans, American Council on Pharmaceutical Education, American College of Clinical Pharmacy, American Nurses Association, American Pharmaceutical Association, American Society of Consultant Pharmacists, American Society of Health-System Pharmacists, Institute for Safe Medication Practices, National Association of Chain Drug Stores, National Community Pharmacists Association, National Council on Prescription Drug Programs, and the Pharmaceutical Care Management Association. Funding for the Framework Project was provided primarily by Aventis Pharmaceuticals, Merck \& Co., Pharmacia Corporation, and Schering-Plough. Other sponsors included Johnson \& Johnson, Novartis, and Pfizer.

\section{DISCLOSURES}

Authors Richard N. Fry and Steven G. Avey are employed by the Foundation for Managed Care Pharmacy, a nonprofit charitable trust that serves as the educational and philanthropic arm of the Academy of Managed Care Pharmacy; author Frederic R. Curtiss performed the majority of work associated with this manuscript prior to becoming editor-in-chief of the Journal of Managed Care Pharmacy. This manuscript underwent blinded peer review and was subject to the same standards as every article published in JMCP.

\section{REFERENCES}

1. Chassin MR, Galvin RW, and the National Roundtable on Health Care Quality. The urgent need to improve health care quality. JAMA. 1998; 280(11):1000-05.

2. Chassin MR. Is health care ready for six-sigma quality? Milbank $Q$ 1998; 76(4):565-91.

3. Schuster MA, McGlynn EA, Brook RH. How good is the quality of healthcare in the United States? Milbank Q. 1998;76(4):517-63.

4. Kohn LT, Corrigan JM, Donaldson MS, eds. To Err Is Human: Building a Safer Health System. Institute of Medicine Committee on Quality of Health Care in America. Washington, DC: National Academy Press; 2000.

5. Kohn LT, Corrigan JM, Donaldson MS, eds. Crossing the Quality Chasm: A New Health System for the 21st Century. Institute of Medicine Committee on
Quality of Health Care in America. Washington, DC: National Academy Press; 2001.

6. Wertheimer AI. Shaping the profession of pharmacy: an overview of seminal events that helped transform pharmacy education and practice during the twentieth century [Appendix A]. In: Pharmacy's Framework for Drug Therapy Management in the 21st Century. Alexandria, VA: Academy of Managed Care Pharmacy; 2002.

7. Midwest Business Group on Health. Reducing the costs of poor-quality health care through responsible purchasing leadership. April 2003. Available at: www.mbgh.org. Accessed May 15, 2003.

8. Medical Errors: The Scope of the Problem [fact sheet]. Rockville, MD: Agency for Healthcare Research and Quality; February 2000. AHRQ publication 00-P037 Available at: http://www.ahrq.gov/qual/errback.htm. Accessed August 18, 2002.

9. Leape LL, Institute of Medicine error figures are not exaggerated. JAMA. 2000;284:95-97

10. MacCondald CJ, Weiner M, Jui SL. Deaths due to medical errors are exaggerated. JAMA. 2000;284:93-95.

11. Weingart SN, Wilson RM, Gibberd, RW, et al. Epidemiology of medical error. BMJ. 2000;320:774-77.

12. Aspinall MB, Whittle J, Aspinall SL, et al. Improving adverse-drug-reaction reporting in ambulatory care clinics at a Veterans Affairs hospital. Am J Health Syst Pharm. May 1, 2002:841-45.

13. Anonymous. FDA handling of ADR reports needs improvement. Am J Health Syst Pharm. February 1, 2000:201-02.

14. Bates DW, Boyle DL, Vander Vliet MB, Schneider J. Leape L. Relationship between medication errors and adverse drug events. J Gen Intern Med. 1995; 10:199-205.

15. Bates DW, Cullen DJ, Laird N, et al. Incidence of adverse drug events and potential adverse drug events: implications for prevention: ADE Prevention Study Group. JAMA. 1995;274:29-34.

16. Gurwitz JH, Field TS, Avorn J, et al. Incidence and preventability of adverse drug events in nursing homes. Am J Med. 2000;109:87-94.

17. Gurwitz JH, Rochon P. Improving the quality of medication use in elderly patients: a not-so-simple prescription. Arch Intern Med. 2002;162(15):1670-72

18. Zhan C, Sangl J. Bierman AS, et al. Potentially inappropriate medication use in community-dwelling elderly: findings from the 1996 Medical Expenditure Panel Survey. JAMA. 2001;286:2823-29.

19. Gurwitz JH, Field TS, Harrold LR, et al. Incidence and preventability of adverse drug events among older persons in the ambulatory setting. JAMA. 2003;289(9):1107-16.

20. Milstein A, Galvin RS, Delbanco SF et al. Improving the safety of health care: the Leapfrog initiative. Eff Clin Pract. 2000;3:313-16.

21. National Quality Forum Consensus Report: Safe Practices for Better Healthcare. May 2003. Available at: http://www.qualityforum.org/ txsafeexecsumm+order6-8-03PUBLIC.pdf. Accessed December 6, 2003.

22. Pew Health Professions Commission. Critical challenges: revitalizing the health professions for the twenty-first century. The third report of the Pew Health Professions Commission. December 1995. Available at: http://www.futurehealth.ucsf.edu/summaries/challenges.html. Accessed December 6, 2003.

23. Anonymous. Professional issues, whom do you trust? Am Med News. January 20, 2003. (Amednews.com Quick View). Available at: http://www.ama-assn.org/sci-pubs/amnews/pick_03/prca0120.htm. Accessed January 22, 2003.

24. Malone DC. Determining the value of pharmacy services-the search for rigorous research designs. J Manag Care Pharm. 2002;8(2):152-55.

25. Malone DC, Carter BL, Billups SJ, et al. An economic analysis of a randomized, controlled, multicenter study of clinical pharmacist interventions for high-risk veterans: the IMPROVE study. Impact of managed pharmaceutical care resource utilization and outcomes in Veterans Affairs medical centers. Pharmacotherapy. 2000;20:1508-16. 
26. Malone DC, Carter BL, Billups SJ, et al. Can clinical pharmacists affect SF-36 scores in veterans at high risk for medication-related problems? Med Care. 2001;39:113-22.

27. Heaton AH, Hansten PD, Martin SL, et al. High frequency of itraconazole prescriptions with potentially interacting medications in a large health care plan. J Manag Care Pharm. 2002;8(3):199-203.

28. Leape LL, Cullen DJ, Clapp MD, et al. Caring for the critically ill patientpharmacist participation on physician rounds and adverse drug events in the intensive care unit. JAMA. 1999;282:267-70.

29. Adams C. The fine print: are too many doctors missing safety alerts on drugs? Wall Street Journal. March 24, 2000:B1.

30. Emslie-Smith AM, Boyle DI, Evans JM, Sullivan F, Morris AD. Contraindications to metformin therapy in patients with type 2 diabetes: a population-based study of adherence to prescribing guidelines. Diabet Med. 2001;18:483-88

31. Holstein A, Nahrwold D, Hinze S, Egberts EH. Contraindications to metformin therapy are largely disregarded. Diabet Med. 1999;16:692-96.

32. Horlen C, Malone R, Bryant B, et al. Frequency of inappropriate metformin prescriptions. JAMA. 2002;287:2504-05

33. Wojcik J. Disease management success prompts second program. Bus Insurance. March 1998;30:6.

34. Connolly C. In N.C., improving worker health—and cutting costs. Washington Post. August 20, 2002:A1, A3.

35. Cranor CW, Christensen DB. The Asheville Project: short-term outcomes of a community pharmacy diabetes care program. J Am Pharm Assoc. 2003; 43(2):149-59.

36. Cranor CW, Bunting BA, Christensen DB. The Asheville Project: long-term clinical and economic outcomes of a community pharmacy diabetes care program. J Am Pharm Assoc. 2003;43(2):173-84.

37. Aventis Managed Care Digest Series 2002. Medical Group Practice Digest:12. Bridgewater, NJ: Aventis; 2002.

38. Isetts BJ, Brown, LM, Schondelmeyer SW, Lenarz LA. Quality assessment of a collaborative approach for decreasing drug-related morbidity and achieving therapeutic goals. Arch Intern Med. 2003;163:1813-20.

39. Institute for Safe Medication Practices. ISMP Medication Safety SelfAssessment for Community-Ambulatory Pharmacy. Available at: www.ismp.org. Accessed March 3, 2004.

40. Supporting documents, Pharmacy's Framework for Drug Therapy Management in the 21st Century. June 2002. Available at: http://www.fmcpnet.org/data/resource/ Framework_Supporting_Documents.pdf. Accessed March 3, 2003.

41. Lopez L. First steps to building pharmacy's framework for drug therapy management in the 21 st century: interviews with customers about pharmacy's role in drug therapy management. Supporting documents, Pharmacy's Framework for Drug Therapy Management in the 21st Century. Alexandria, VA: Academy of Managed Care Pharmacy; 2002. Available at: http://www.fmcpnet.org/data/ resource/Framework_Supporting_Documents.pdf. Accessed March 3, 2003.

42. The Self-Assessment Tool. Pharmacy's Framework for Drug Therapy Management in the 21st Century-A Quality Improvement Tool. Alexandria, VA Academy of Managed Care Pharmacy; 2002. Available at: http://www.fmcnet.org/ data/resource/Framework_Self_Assessment_Tool.pdf. Accessed December 6, 2003.

43. de Brantes F, Galvin RS, Lee TH. Bridges to excellence: building a business case for quality care. J Clin Outcomes Manage. 2003;10(8):439-46.

44. Shojania KG, Duncan BW, McDonald KM, et al, eds. Making Health Care Safer: A Critical Analysis of Patient Safety Practices. Rockville, MD: Agency for Healthcare Research and Quality; 2001. Evidence Report/Technology Assessment No. 43. AHRQ publication 01-E058.

45. Fortescue EB, Kaushal R, Landrigan CP, et al. Prioritizing strategies for preventing medication errors and adverse drug events in pediatric inpatients. Pediatrics. 2003;111(4):722-29.
46. Oks D, Westcott RT, eds. Certified Quality Manager Handbook. 2nd ed. 2001. Available at: http://qualitypress.asq.org/perl/catalog. Accessed March 29, 2003.

47. Berwick DM. As Good As It Should Get: Making Health Care Better in the New Millennium. Boston, MA: Institute for Healthcare Improvement; 1998. Available at: http://www.ihi.org/newsandpublications/articles/ ci080lasgoodas.asp. Accessed August 15, 2002.

48. Koretz BK, Moore AA. Assessment of the geriatric patient: a practical approach. J Clin Outcomes Manage. July 2001;8(7):35-40

49. Medicare Payment Advisory Commission (MedPAC). Report to the Congress-Medicare Coverage of Nonphysician Practitioners. June 2002:23. Available at: www.medpac.gov/publications/congressional_reports/jun02_ NonPhysCoverag.pdf. Accessed June 29, 2002.

50. Anonymous. Let's collaborate. Drug Top. September 1, 2003:58-64, 67.

51. Flynn EA, Barker KN, Carnahan, BJ. National observational study of prescription dispensing accuracy and safety in 50 pharmacies. J Am Pharm Assoc 2003;43(2): 191-200.

52. Meza JP, Webster DS. Patient preferences for laboratory test results notification. Am J Manag Care. 2000;6(12):1297-1300.

53. Murray E, David H, Tai SS, et al. Randomized controlled trial of an interactive multimedia decision aid on hormone replacement therapy in primary care. BMJ. 2001;323:490-93.

54. Dwight-Johnson M, Unutzer J, Sherbourne C, et al. Can quality improvement programs for depression in primary care address patient preferences for treatment? Med Care. 2001;39:934-44.

55. Lopez L, Wertheimer AI. Designing a framework for pharmacy practice: a look at consumer reactions and expectations. J Manag Care Pharm. 2001; 7(3):193-200.

56. Shekelle PG, Ortiz E, Rhodes S, et al. Validity of the Agency for Healthcare Research and Quality Clinical Practice Guidelines-how quickly do guidelines become outdated? JAMA. 2001;286:1461-67.

57. Agency for Healthcare Research and Quality. National Quality Measures Clearinghouse (NQMC). Available at: http://www.qualitymeasures.ahrq.gov/. Accessed March 1, 2003.

58. Cabana MD, Rand CS, Powe NR, et al. Why don't physicians follow clinical practice guidelines? A framework for improvement. JAMA. 1999;282(15): 1458-65.

59. Hayward RS. Clinical practice guidelines on trial. Can Med Assoc J. 1997:156:1725-27.

60. Lomas J, Anderson GM, Karin D-P, et al. Do practice guidelines guide practice? The effect of a consensus statement on the practice of physicians. New Engl J Med. 1989;321(19):1306-11.

61. Woolf SH. Practice guidelines: a new reality in medicine. III. Impact on patient care. Arch Intern Med. 1993;153:2646-55.

62. James B. Quality improvement opportunities in health care-making it easy to do it right. J Manag Care Pharm. 2002;8(5):394-99.

63. Dexter PR, Perkins S, Overhage JM, et al. A computerized reminder system to increase the use of preventive care for hospitalized patients, New Engl J Med. 2001;345(13):965-70.

64. Weed LL. Opening the black box of clinical judgment-an overview. BMJ. 1999;319:1-4. Available at: www.bmj.com/cgi/reprint/319/7220/1279.pdf. Accessed March 5, 2003.

65. Sullivan SD, Lyles A, Luce B, et al. AMCP guidance for submission of clinical and economic evaluation data to support formulary listing in U.S. health plans and pharmacy benefits management organizations. J Manag Care Pharm. 2001;7(4):272-82

66. Marshall T. Coronary heart disease prevention: insights from modeling incremental cost effectiveness. BMJ. 2003;327:1264-66.

67. Glauber JH. Does the HEDIS asthma measure go far enough? Am J Manag Care. June 2001;5(6):575-79. 
68. Knapp K, Blalock SJ, Black BL. ASHP survey of ambulatory care responsibilities of pharmacists in managed care and integrated health systems-2001. Am J Health Syst Pharm. November 15, 2001:2151-66.

69. Landro L. Hospitals' technology gap widens. Wall Street Journal. July 16, 2002:D3. Available at: www.hhnmag.com. Accessed July 16, 2002.

70. Mount JK. Organization culture and effecting change in pharmacy in the 21 st century. Supporting documents, Pharmacy's Framework for Drug Therapy Management in the 21st Century. Alexandria, VA: Academy of Managed Care Pharmacy; 2002. Available at: http://www.fmcpnet.org/data/resource/ Framework_Supporting_Documents.pdf. Accessed March 3, 2003.

\section{AMCP DOCUMENTS PRECEDING FRAMEWORK} (SEE ABSTRACT)

- Catalog of Pharmacy Quality Indicators. Alexandria, VA: Academy of Managed Care Pharmacy; 1997.

- Pharmacy Quality Council. Summary of National Pharmacy Quality Measures. Alexandria, VA: Academy of Managed Care Pharmacy; February 1999. 